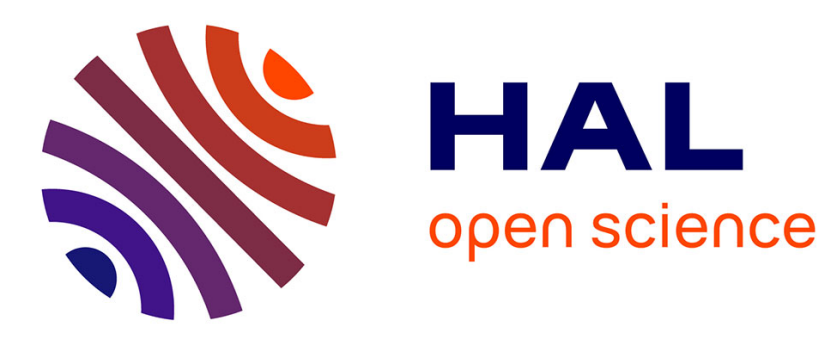

\title{
Study of Water Freezing in Nano-Channels of Supramolecular Structure Formed by Wedge-Shaped Amphiphilic Molecules
}

Kseniia Grafskaia, Denis Anokhin, A.F. Akhkiamova, Dimitri Ivanov

\section{- To cite this version:}

Kseniia Grafskaia, Denis Anokhin, A.F. Akhkiamova, Dimitri Ivanov. Study of Water Freezing in Nano-Channels of Supramolecular Structure Formed by Wedge-Shaped Amphiphilic Molecules. Key Engineering Materials, 2019, 816 (23), pp.139-145. 10.4028/www.scientific.net/KEM.816.139 . hal03095929

\section{HAL Id: hal-03095929 \\ https://hal.science/hal-03095929}

Submitted on 5 Jan 2021

HAL is a multi-disciplinary open access archive for the deposit and dissemination of scientific research documents, whether they are published or not. The documents may come from teaching and research institutions in France or abroad, or from public or private research centers.
L'archive ouverte pluridisciplinaire HAL, est destinée au dépôt et à la diffusion de documents scientifiques de niveau recherche, publiés ou non, émanant des établissements d'enseignement et de recherche français ou étrangers, des laboratoires publics ou privés. 


\section{Study of Water Freezing in Nano-Channels of Supramolecular Structure}

\section{Formed by Wedge-Shaped Amphiphilic Molecules}

K.N. Grafskaia1,2,a, D.V. Anokhin1,2,4,b*, A.F. Akhkiamova1,3,4,c and D.A. Ivanov1,2,4,d

1Institute of Problems of Chemical Physics, Russian Academy of Sciences, Semenov Av. 1, Chernogolovka, Moscow region, 142432, Russia

2Moscow Institute of Physics and Technology, Institutskiy per. 9, Dolgoprudny, 141700, Russia 3ESRF - The European Synchrotron Radiation Facility and Partnership for Soft Condensed Matter (PSCM), 71, Avenue des Martyrs, 38043 Grenoble CEDEX 9, France 4 Lomonosov Moscow State University, Faculty of Fundamental Physical and Chemical Engineering, GSP-1, 1-51 Leninskie Gory, Moscow, 119991, Russia. axgrafskaya@gmail.com, bdeniano@yahoo.com, cazaliia.akhkiamova@gmail.com, ddimitri.ivanov.2014@gmail.com

Keywords: Amphiphilic molecules, self-assembly, geometrical confinements, water freezing Abstract. Phase behavior and supramolecular structure stability of wedge-shaped mesogens at negative temperature have been studied for the first time. The effect of geometrical confinement on water crystallization in different channels was examined. The role of local ordering of linear alkyl groups on stability of the nano-channels during water freezing was enlighten.

\section{Introduction}

Among amphiphilic liquid-crystalline (LC) compounds, wedge-shaped derivatives sulfonic acid and it's sodium, imidazole and pyridine salts, etc., are have been well studied. [1] These compounds can form not only lyotropic phases typical for the majority of LC systems in aqueous systems, but thermotropic mesophases in solid state as well. $[2,3]$ The type of the mesophase depends on the mesogens' chemical structure and preparation conditions. Previously, we have shown that the compounds with polymerizable groups are able to organize in cubic (Cub) or columnar (Colhd) supramolecular structures with defined morphology during heating or swelling processes in the water pores $[4,5]$. The prepared structure can be fixed by photopolymerization of acetylene or methacrylic groups, giving a mechanically stable film with developed polymer network of bound mesogens [6].

For mesogen with linear side chains, we have shown the existence of metastable bicontinuous 
cubic phases in a wide temperature range due to the local ordering of the alkyl chains. In this case, reversible "activation" of thin films is possible during heating above the melting point of subcrystals. However, this method has certain disadvantages. First of all, activation occurs only under saturated vapors of methanol, which is able to penetrate through the amorphous alkyl phase at elevated temperature. Second, water evaporation during heating reduces mechanical stability of the polymerized film. Accordingly, a new activation method of self-assembled thin films was developed based on cooling of the samples below $0^{\circ} \mathrm{C}$ in humid atmosphere. The effect of water crystallization in the geometric constraints of nanochannels on the activation process was established.

\section{Materials and Methods}

The synthesis of sodium 4'-[3", 4", 5"-tris(dodecyloxy)benzoyloxy]-azobenzene-4-sulfonate (C12-Na) and sodium 4'-[3", 4", 5'"-tris-(octyloxy)benzoyloxy]azobenzene-4-sulfonate (C8-Na) was described in our previous papers. $[7,8]$

Grazing-incidence small-angle X-ray scattering (GISAXS) measurements were performed at the BM26 and ID10 beamlines of the European Synchrotron Radiation Facility (ESRF) in Grenoble (France) using a custom-designed environmental chamber. [9,10]

The energy of X-ray photons was $12 \mathrm{keV}$. The s-axis $(|s|=2 \sin \gamma / \mathrm{l}$, where $\gamma$ is the Bragg angle, I is the wavelength and $|s|$ is the norm of the s-vector) was calibrated using several diffraction orders of silver behenate. X-ray patterns were recorded using a 2D Pilatus $1 \mathrm{M}$ camera. The $\mathrm{X}$-ray data analysis, including back-ground subtraction and radial integrations of the $2 \mathrm{D}$ patterns was accomplished using home-built routines designed within the IgorPro software package (Wavemetrics Ltd). For the GISAXS experiments, thin films of C12-Na and C8-Na were prepared from chloroform solutions $(20 \mathrm{mg} / \mathrm{ml}$ ) by spin-coating $(500 \mathrm{rpm} / \mathrm{min}$ ) on a silicon wafer substrate. The phase composition of the thin films at different temperatures was addressed by in situ heating and cooling of the samples in temperature range from $-50^{\circ} \mathrm{C}$ to $100{ }^{\circ} \mathrm{C}$. The change in the phase structure during the water uptake process on thin films was also monitored in situ controlled relative humidity (RH) and temperature.

AFM Imaging was performed in tapping mode using Asylum Research Cypher-S AFM instruments using (equipped with) Oxford Instruments AC240TS medium soft silicon cantilevers with a resonance frequency $67 \mathrm{kHz}$ and spring constant $1.82 \mathrm{~N} / \mathrm{m}$, measured by the thermal noise method. The AFM images were analyses using the open source software Gwyddion. 
Results

The diffraction pattern of $\mathrm{C} 8 \mathrm{Na}$ thin film after swelling upon water vapor for two hours at room temperature demonstrates the presence of two meridional peaks with $d$-spacings $d 1=57.0 \AA$ and $d 2$ = 61.1 Å related to two phases, denoted as 1 and 2, respectively (Fig. 1a). During cooling, a strong increase in the phase 1 parameter and a gradual increase in the phase 2 parameter can be observed (Fig. 1b). At $0{ }^{\circ} \mathrm{C}$ the reflection of phase 1 disappears probably because of destruction. On the contrary, the reflex of phase 2 is maintained with constant $\mathrm{d} 2$ below $0{ }^{\circ} \mathrm{C}$. Further cooling to $-25^{\circ} \mathrm{C}$ did not cause any noticeable changes in the structure (Fig. 1c). Due to the presence of saturated water vapor in the chamber, at $-50^{\circ} \mathrm{C}$ we detect formation of ice on the film surface and vanishing of the phase 2 (Fig. 1d). Fig. 1e shows the changes in the parameters of both phases during cooling from $25^{\circ} \mathrm{C}$ to $-50^{\circ} \mathrm{C}$. The $\mathrm{d}$-spacing of the phases 1 and 2 increase by $30 \%$ and $7 \%$, respectively. It can be assumed that phase 1 is lamellar one containing two-dimensional water channels. The width of the channels increases during precipitation of water on the film surface below dew point. A weak change of phase 2 parameter indicates that it does not contain water channels. Probably, for these structure hydrophilic regions are not connected to the film surface, that prevents the water vapor diffusion from the atmosphere. In this case, it is the lamellar phase that is equilibrium in the swollen state that is in good agreement with our previous works. [11] Subsequent heating to room temperature leads to recovery of only phase 2 in the region of $71^{\circ} \mathrm{C}$.
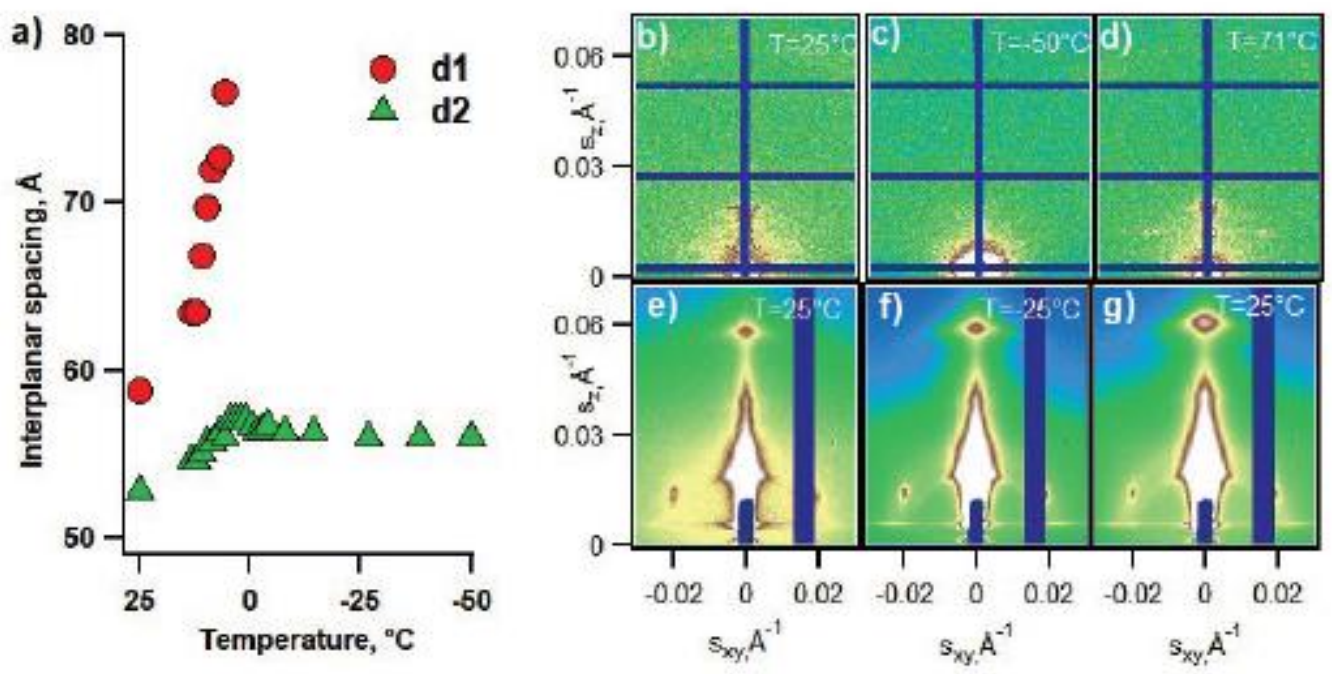

Fig. 1 - The change of lamellar phases lattice parameter during cooling of the swollen thin film C8Na (a). Two-dimensional GISAXS patterns of the swollen C8Na sample during thermal treatment: initial structure at $25^{\circ} \mathrm{C}$ (b); after cooling to $-50^{\circ} \mathrm{C}$ (c); after subsequent heating to $71^{\circ} \mathrm{C}(\mathrm{d})$; and dry $\mathrm{C} 8 \mathrm{Na}$ sample: initial structure at $25^{\circ} \mathrm{C}(\mathrm{e})$; after cooling to $-25^{\circ} \mathrm{C}(\mathrm{f})$, after subsequent heating to $25^{\circ} \mathrm{C}(\mathrm{g})$. 
To identify phase 2 we have studied the structure of C8Na thin film dried at $200^{\circ} \mathrm{C}$ and measured in a dry nitrogen atmosphere (Fig. 1e, f, g). At room temperature diffractogram reveal pseudohexagonal phase with lattice parameters aph $=51.0 \AA$ and $b p h=46.8 \AA, \gamma p h=66^{\circ}$ (Fig. 1e). It is important to mention that the position of the meridional peak with $d=51.0 \AA$ corresponds to phase 2 mentioned above for the swollen film. Thus, phase 2 is pseudo-hexagonal columnar, and characterizes the structure of material in the absence of water channels. Cooling the sample to $-25^{\circ} \mathrm{C}$ and subsequent heating to room temperature does not lead to significant changes of the structure, which indicates the stability of the columnar phase at temperature below zero (Fig. 1f,g). Based on the evolution of the C8Na thin film structure in the heating and cooling cycles, we conclude that the pseudohexagonal phase is stable for the dry film while the lamellar phase - for the swollen one. When the swollen film is cooled down, a sharp increase in the alam parameter is observed due to intense water absorption below the dew point. In this case, the width of the twodimensional

water channel in the swollen lamellar phase can be calculated as the difference in the $\mathrm{d}$-spacings $\mathrm{d} 1$ and $\mathrm{d} 2$. Thus, cooling to $0^{\circ} \mathrm{C}$ is an effective way to accelerate the swelling process upon saturated atmosphere of water vapor, providing an increase of the water channel width from 6 to $20 \AA$. Below $0{ }^{\circ} \mathrm{C}$ water crystallizes in the confined geometry of nanochannels resulting in braking of the soft LC phase. In contrast, cooling of film containing the columnar phase does not have a significant effect.

An increase in the length of alkyl groups from octyl to dodecyl result in change of the phase behavior of the amphiphilic mesogen (Fig. 2,3). The initial state of the C12Na thin film in the swollen state shows a lamellar phase (alam $=53.1 \AA$ ) (Fig. 2a). Cooling the sample from room temperature to $-25^{\circ} \mathrm{C}$ causes a slight decrease of the lattice parameter (Figure $2 \mathrm{~b}$ ). Reheating to room temperature leads to the recovery of the original structure (Fig. 2c). A weak change in the parameters of the swollen lamellar phase can be explained by hydrophobic nature of the film surface formed by alkyl chains. The regular hydrophobic surface limits diffusion of water molecules to polar regions of the $\mathrm{LC}$ phase. Assuming normal orientation of the $\mathrm{C} 12 \mathrm{Na}$ molecules in respect to the lamellar layer, we can estimate water channel width $r$ as:

$$
r=a_{\mathrm{lam}}-2 l
$$

where $a_{\text {lam }}$ is the parameter of the lamellar phase, $l$ is the length of the molecule ( $24 \AA$ ). The found channel width is $5 \AA$, which is significantly less than critical nuclei size of ice at $-50{ }^{\circ} \mathrm{C}$ - about $13 \AA[12,13]$. Thus, the small width of water channels in the swollen C12Na structure prevents the formation of ice nuclei down to $-50{ }^{\circ} \mathrm{C}$ and provides high stability of the lamellar phase at low 
temperature.

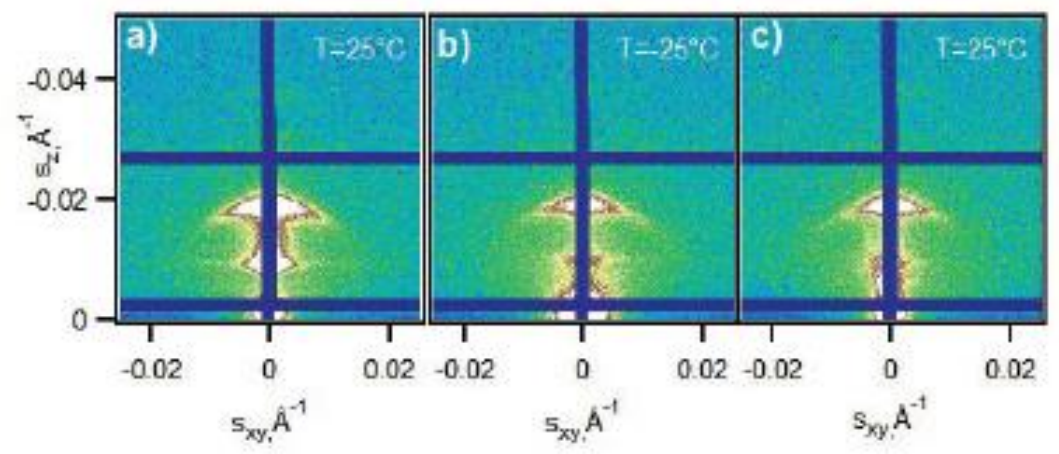

Fig. 2 - Two-dimensional GISAXS patterns of swollen C12Na samples during thermal treatment: initial at $25^{\circ} \mathrm{C}(\mathrm{a})$; after cooling to $-25^{\circ} \mathrm{C}(\mathrm{b})$, after subsequent heating to $25^{\circ} \mathrm{C}(\mathrm{c})$.

The dry film structure of $\mathrm{C} 12 \mathrm{Na}$ at $25^{\circ} \mathrm{C}$ is similar to $\mathrm{C} 8 \mathrm{Na}$ (Fig. 3a). A characteristic texture of the monoclinic columnar phase is observed with the following parameters: amon $=57.6 \AA$, bmon $=51.4 \AA, \gamma=55^{\circ}$. Cooling of dry C12Na film leads to certain disordering of the columnar phase and insignificant change of the lattice parameters (Fig. 3c). During heating from -25 to $25^{\circ} \mathrm{C}$ the initial structure is fully restored (Fig. 3d, e). Thus, thermodynamically stable at room temperature columnar phase does not undergo changes upon cooling.

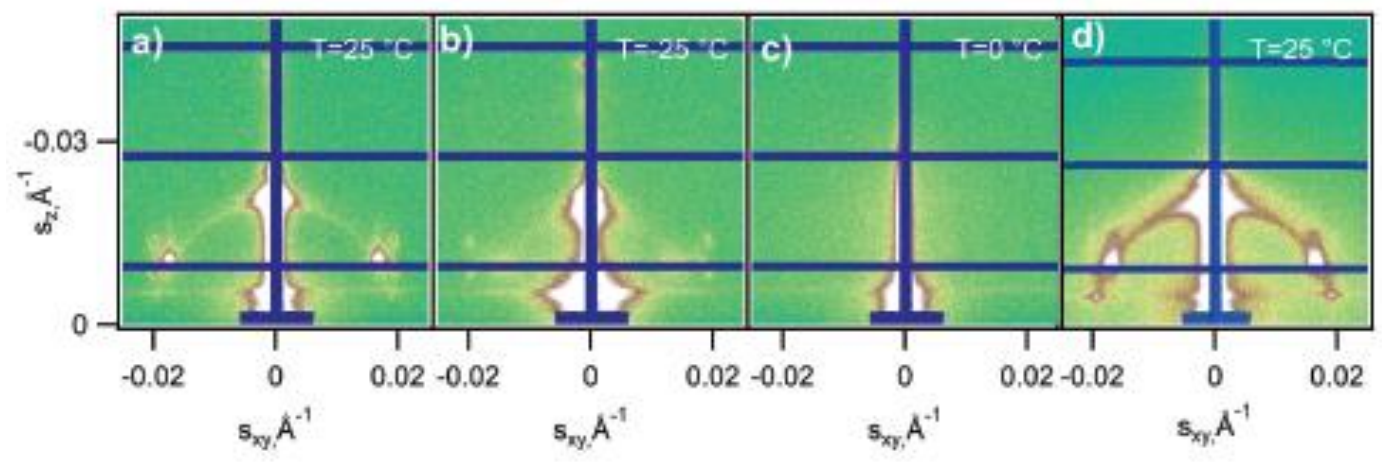

Fig. 3 - Two-dimensional GISAXS patterns of dry C12Na samples during thermal treatment: initial at $25^{\circ} \mathrm{C}(\mathrm{a})$; after cooling to $-25^{\circ} \mathrm{C}(\mathrm{b})$, after subsequent heating to $0^{\circ} \mathrm{C}(\mathrm{d})$, to $25^{\circ} \mathrm{C}(\mathrm{e})$.

The reason for the stability of the lamellar phase of $\mathrm{C} 12 \mathrm{Na}$ during cooling can be understood from the analysis of wide-angle reflections (Fig.4). On the WAXS pattern of the swollen film one can see equatorial reflections with d-spacings of 4.5 and $4.0 \AA$ (Fig. 4a). In our previous work, we have observed these reflections in the columnar monoclinic and cubic gyroid phase [14]. For wedge-shaped mesogens, they correspond to the local ordering of the alkyl chains with formation of nanometer-sized crystals in the total supramolecular cell [15]. In this case, the alkyl chains are oriented perpendicular to the substrate.

Thus, in the lamellar phase of the swollen thin film we observe crystallization of the alkyl chains 
providing formation of a rigid physical network and stabilization of the supramolecular structure at low temperature. During following heating to $25^{\circ} \mathrm{C}$, wide-angle reflections are not observed, which indicates the destruction of alkyl nanocrystals caused by water freezing on the film surface. (Fig. 4b). However, the supramolecular lamellar structure of the $\mathrm{C} 12 \mathrm{Na}$ film remains up to $100^{\circ} \mathrm{C}$, where transforms to hexagonal phase with parameter ahex $=58.0 \AA$. Probably due to the lack of a selected orientation of the alkyl chains in the columns, the formation of a regular physical network in the dry film does not occur.

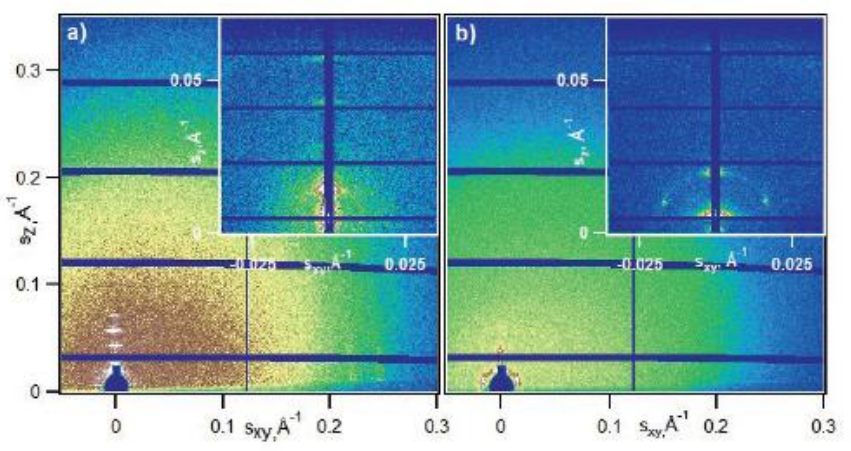

Fig. 4 - Two-dimensional GISAXS and GIWAXS (inset) patterns of the swollen (a) and dry (b) sample $\mathrm{C} 12 \mathrm{Na}$ at room temperature.

It is worth mentioning that subsequent cooling of the film from $100^{\circ} \mathrm{C}$ to $25^{\circ} \mathrm{C}$ in the presence of water vapor leads to the recovery of the lamellar structure with wide-angle equatorial reflections. Probably, the diffusion of water vapor through the amorphous alkyl matrix occurs much faster than through the crystalline regions.

The change in the LC phase in C12Na thin films upon swelling is confirmed by AFM images (Fig. 5). The dry film is characterized by a rough topology with a periodicity about $200 \AA$ (Fig. 5a). The height of the terraces is $50-60 \AA$, which corresponds to the columns diameter. After exposure in a humid atmosphere, a sharp decrease in roughness occurs that is typical of lamellar phases (Figure 5b). The height of the terraces increases to $80-100 \AA$, which significantly exceeds the lattice parameter alam $=53 \AA$. This can be explained by a more effective swelling process of a film with smaller thickness (1000-3000 $\AA$ ) used in the AFM experiments. 

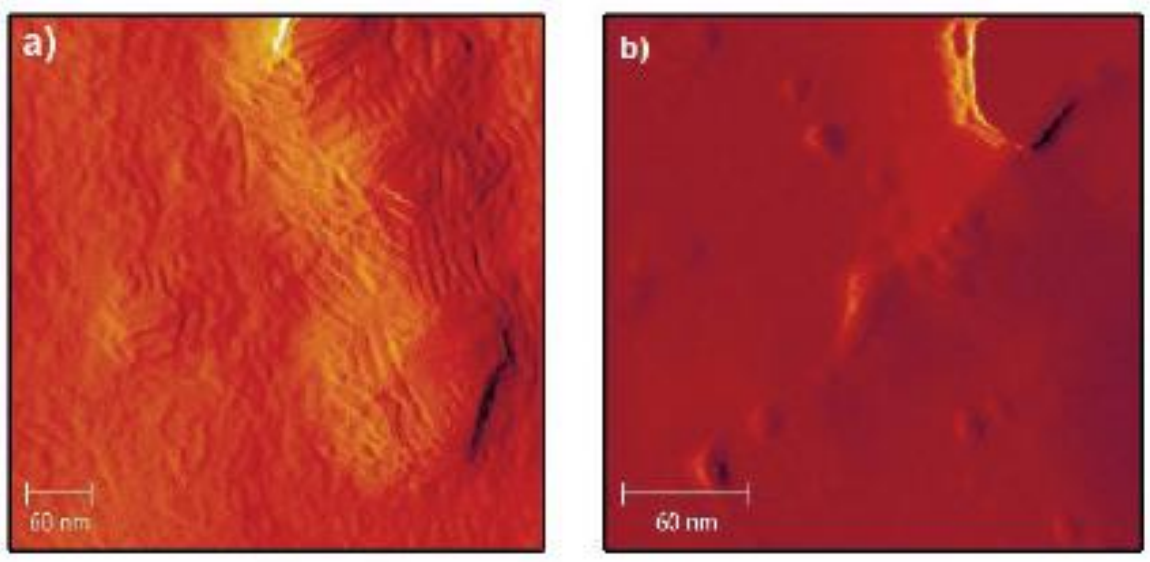

Fig. 5 - AFM phase images of the C12Na sample in the dry (column phase) (a) and swollen (lamellar phase) (b) state at room temperature.

\section{Summary}

By X-ray diffraction analysis and atomic-force microscopy the phase behavior of thin films of wedge-shaped mesogens at low temperatures in dry and swollen state was investigated for the first time. Dry samples are characterized by the presence of a columnar phase, whereas in the swollen thin films reveal lamellar phase containing two-dimensional water channels. For a sample with octyl side groups, cooling below room temperature results in an increase in the width of the water channel from 6 to $20 \AA$ followed by LC structure vanishing $0{ }^{\circ} \mathrm{C}$ due to water freezing. Mesogen bearing dodecyl groups show excellent channel stability down to $-50{ }^{\circ} \mathrm{C}$ due to the presence of physical network formed by nanocrystals of the alkyl chains. The rigid framework prevents film swelling during cooling and suppress ice nucleation in narrow $(5 \AA)$ channels. The obtained results are important for understanding of supramolecular systems formation at different hierarchical levels and help in developing of new approaches in fabrication of self-organized films with required morphology.

Acknowledgments

The authors acknowledge the Ministry of Science and High Education of the Russian Federation for financial support (contract No. 14.587.21.0052 (RFMEFI58718X0052)). The work was done on the theme of the state task, № 01201361836. We thank ESRF for beamtime at BM26, ESRF's Partnership for Soft Condensed Matter (PSCM) for support, A.Panzarella for AFM consultation, and D.Pontoni for assistance and advice.

\section{References}

[1] K. Binnemans, lonic Liquid Crystals, Chem. Rev. 105 (2005) 4148-4204. 
[2] C. Tschierske, Molecular self-organization of amphotropic liquid crystals, Progr. Polym. Sci. 21 (1996) 775-852.

[3] J.W. Goodby, Liquid Crystal Phases Exhibited by Some Monosaccharides, Mol. Cryst. Liq. Cryst. 110 (1984) 205-219.

[4] J.J. Hernandez, H. Zhang, Y. Chen, M. Rosenthal, M.D. Lingwood, M. Goswami, M. Möller, L.A. Madsen, D.A. Ivamov, Bottom-Up Fabrication of Nanostructured Bicontinuous and Hexagonal lon-Conducting Polymer Membranes, Macromolecules. 14 (2017) 5392-5401.

[5] Y. Chen, M.D. Lingwood, M. Goswami, B.E. Kidd, J.J. Hernandez, M. Rosenthal, D.A. Ivanov, J. Perlich, H. Zhang, X. Zhu, M. Möller, L.A. Madsen, Humidity-modulated phase control and nanoscopic transport in supramolecular assemblies, Journal of Physical Chemistry B. 11 (2014) 3207-3217.

[6] H. Zhang, L. Li, M. Moller, X. Zhu, J.J. Hernandez, M. Rosental, D.A. Ivanov, From ChannelForming lonic Liquid Crystals Exhibiting Humidity-Induced Phase Transitions to Nanostructured Ion-Conducting Polymer Membranes, Advanced Materials. 25 (2013) 3543-3548.

[7] X. Zhu, B. Tartsch, U. Beginn, M. Möller, Wedge-Shaped Molecules with a Sulfonate Group at the Tip-A New Class of Self-Assembling Amphiphiles, Chem. - Eur. J. 10 (2004) 3871-3878. [8] X. Zhu, U. Beginn, M. Möller, R.I. Gearba, D.V. Anokhin, D.A. Ivanov, Self-Organization of Polybases Neutralized with Mesogenic Wedge-Shaped Sulfonic Acid Molecules: An Approach toward Supramolecular Cylinders, J. Am. Chem. Soc. 128 (2006) 16928-16937.

[9] K.N. Grafskaia, D.V. Anokhin, J.J. Hernandez, D.A. Ivanov, In situ studies of molecular selfassembling during the formation of ionconducting membranes for fuel cells, Appl. Mech. Mater. 792 (2015) 623-628.

[10] K. Grafskaia, B. Zimka, X. Zhu, D. Anokhin, D. Ivanov, Engineering of ion channels topology in self-assembled wedge-shaped amphiphiles by combination of temperature and solvent vapor treatment, AIP Conference Proceedings 1748 (2016) 040009.

[11] A. Dolgopolov, K.N. Grafskaia, D.V. Anokhin, D.E. Demco, X. Zhu, D.A. Ivanov, M. Möller, Humidity-induced formation of water channels in supramolecular assemblies of wedge-shaped amphiphiles: the effect of the molecular architecture on the channel topology, Phys.Chem.Chem.Phys. 19 (2017) 7714.

[12] J. Liu, C.E. Nicholson, S.J. Cooper, Direct Measurement of Critical Nucleus Size in Confined Volumes, Langmuir. 23 (2017) 7286-7292.

[13] T. Mizuguchi, Critical nucleus size for crystallization of supercooled liquids in two 
dimensions, Physical Review E. 95 (2017) 042804.

[14] K.N. Grafskaia, D.V. Anokhin, B.I. Zimka, I.A. Izdelieva, X. Zhu, D.A. Ivanov, An "on-off" switchable cubic phase with exceptional thermal stability and water sorption capacity, Chem. Commun. 99 (2017) 13217-13220.

[15] K.N. Grafskaia, J.J. Hernandez Rueda, X. Zhu, V.M. Nekipelov, D.V. Anokhin, M. Moeller, D.A. Ivanov, Designing the topology of ion nano-channels in the mesophases of amphiphilic wedge-shaped molecules, Phys.Chem.Chem.Phys. 17 (2015) 30240-30247. 